\title{
Red alert: Marxist approaches to science fiction cinema - Aproximações entre ficção científica e marxismo \\ Red alert: Marxist approaches to science fiction cinema
}

Gabriel Carneiro ${ }^{1}$

Jornalista, cineasta, crítico e pesquisador de cinema, mestre em Multimeios pela Universidade Estadual de Campinas (Unicamp). Sócio fundador da Abraccine - Associação Brasileira de Críticos de Cinema. E-mail: ghpcarneiro@gmail.com 
Resumo: o texto aponta os principais aspectos e abordagens do livro de ensaios Red alert: Marxist approaches to science fiction cinema, organizado por Alfredo Suppia e Ewa Mazierska, que busca relacionar filmes de ficção científica e a filosofia marxista.

Palavras-chave: ficção científica; marxismo; cinema de gênero.

Abstract: this text points out the main aspects and approaches of the essays book Red alert: Marxist approaches to science fiction cinema, edited by Alfredo Suppia and Ewa Mazierska, which relates science fiction movies and the Marxist philosophy.

Keywords: science fiction; Marxism; genre cinema. 
Em tempos de avanços de uma ideologia fascista no seio do capitalismo neoliberal financeiro, parece oportuno o lançamento, em 2016, pela Wayne State University Press, do compêndio de artigos em inglês Red alert: Marxist approaches to science fiction cinema, organizado pelo brasileiro Alfredo Suppia e pela polonesa Ewa Mazierska. A proposta do livro é demonstrar como alguns filmes inscritos dentro do gênero narrativo ficção científica manifestam aspectos da filosofia econômica, social e política de Karl Marx e de pensadores que continuaram seu trabalho no último século e meio.

Suppia e Mazierska partem do princípio de que todo filme é político e, mais ainda, de que a ideia, um tanto preconceituosa, de que o cinema de gênero (mais especificamente, o de ficção científica) é desprovido de uma visão crítica e voltado para os problemas do mundo é falsa. Para tal, os editores buscam diferentes olhares para produções de diversas épocas e realidades, do mundo inteiro; várias até em coproduções internacionais, que, em si só, apontam para uma ideia de transnacional, segundo a introdução do livro (MARZIESKA; SUPPIA, 2016, p. 13-14), similar ao princípio marxista. Também na introdução, os organizadores fazem uma interessante leitura para aproximar os universos da ficção científica e do marxismo: ambos buscam, de forma científica, apontar cenários (utópicos el ou distópicos) para o futuro, a partir das questões contemporâneas (MARZIESKA; SUPPIA, 2016, p. 3). Tais apontamentos, mesmo que não se desdobrem ao longo do livro, refletem os desejos de quase incorporar Marx dentro da literatura de ficção científica, que preconiza o futuro, analisa o presente e, muitas vezes, propõe soluções para um mundo que lhe pareça melhor.

A relação da ficção científica com o marxismo não é nova. Já em 1895, H. G. Wells se baseou nos pensamentos de Marx e Friedrich Engels para escrever A máquina do tempo. Red alert não parece buscar uma originalidade nesse cruzamento, e sim investigar as diferentes confluências de um pensamento de esquerda no cinema de ficção científica.

Além da introdução, Red alert conta com nove artigos. O que talvez seja mais interessante no livro é que ele contempla duas retóricas mestras do pensamento marxista. De um lado, nos três primeiros capítulos, acompanhamos a vertente utópica, em que o comunismo está ao alcance, o socialismo é (quase) presente e o radicalismo do empoderamento de classes menos favorecidas aponta uma esperança. Nos seis últimos, vemos filmes em que a hegemonia do capitalismo selvagem se desdobra na derrocada dos direitos humanos e sociais, num futuro pessimista sem escrúpulos. O recorte de Suppia e Mazierska não parece à toa. Com o avanço do capitalismo neoliberal e o fim do bloco soviético, nos anos 1990, parece não haver mais esperança no cinema de ficção científica, deduzimos. Os filmes utópicos 
ficaram para trás, entre os anos 1950 e 1980, enquanto a desilusão com os rumos da humanidade domina as narrativas dos últimos 15-20 anos. A linha editorial é política, ideológica; dizem já na conclusão do capítulo introdutório: “queremos alertar os leitores sobre os perigos de aceitar as estruturas econômicas do capitalismo e suas formas de vivência, especialmente em sua versão extrema do neoliberalismo" (MARZIESKA; SUPPIA, 2016, p. 21).

\section{O marxismo utópico}

No primeiro artigo, "First contact or primal scene: Communism meets Real Socialism meets Capitalism in early Czechoslovak science fiction cinema”, Petra Hanáková analisa como dois filmes tchecos que apresentam viagem espacial, Muz z prvního století (1962), de Oldrich Lipský, e Viagem ao fim do universo (Ikarie XB 1, 1963), de Jindrich Polák, idealizam o futuro do planeta, quando se haverá enfim alcançado o comunismo. Em ambos, realizados dentro dos esforços da propaganda soviética e da Cortina de Ferro, o comunismo deixa de ser utópico e se transforma em realidade.

O texto de Hanáková ganha um interessante contraponto em "Soviet and post-Soviet images of Capitalism: ideological fissures in Marek Piestrak's PolishEstonian coproductions". No texto, Eva Näripea investiga três filmes do polonês Marek Piestrak feitos em coprodução com a Tallinnfilm, da Estônia: Test pilota Pirxa (1979), A maldição do vale das serpentes (Klatwa doliny wezy, 1987) e Lza ksiecia ciemnosci (1992). Interessam a Näripea justamente os paradoxos do socialismo soviético tardio. Piestrak, que é considerado um dos piores cineastas poloneses pela crítica local, devido à precariedade das produções, ganhou status de cult ao redor do mundo. Para a autora, isso reflete a ambiguidade dos seus filmes. Enquanto, na superfície, eles refletem os valores propagados pelo governo socialista, é possível depreender uma série de críticas a esse modelo, incluindo, por exemplo, a representação da mulher na sociedade - que, no discurso, prega igualdade, mas que, na prática, invisibiliza as mulheres tal como no modelo patriarcal capitalista.

No terceiro artigo, "Paying freedom dues: Marxism, Black Radicalism, and Blaxploitation science fiction”, Mark Bould localiza discursos anticoloniais e demonstra contradições nas relações de classe e raça em nove filmes Blaxpoitation dos anos 1970 que tangenciam a ficção científica. Bould parte de apontamentos de Marx sobre a escravidão e dos escritos dos pensadores negros Frantz Fanon e Huey P. Newton para esboçar uma relação entre o pensamento marxista e os filmes em questão. 


\section{O capitalismo distópico}

Nos seis capítulos seguintes, por mais que as bases teóricas sejam diferentes, a linha-mestra de análise parece ser a mesma: os filmes apontam que, se as relações econômicas e sociais continuarem como estão, o futuro do planeta será desprovido de empatia pelo próximo e será dominado pela lógica da acumulação de riquezas justamente para controle dos outros. Na maioria dos casos analisados, os filmes tomam perspectiva das classes trabalhadoras e retratam as classes dominantes de maneira estereotipada, de forma a induzir uma moral.

Nos textos de Sherryl Vint ("The biopolitics of globalization in Damir Lukacevic's Transfer", capítulo 4), Ewa Mazierska ("Representation of 'Gaming Capitalism' in Avalon and Gamer", capítulo 7) e Alfredo Suppia ("Remote exploitations: Alex Rivera's materialist SF in the age of Cognitive Capitalism”, capítulo 8) vemos como não é a força de trabalho, e sim o corpo que se transforma na principal matéria-prima do proletariado.

Isso é mais evidente no alemão Transfer (2010), de Damir Lukacevic. Em seu artigo, Sherryl Vint parte de pesquisas sociológicas recentes acerca do mercado negro de órgãos para desenvolver um raciocínio de cunho marxista sobre o futuro projetado em Transfer. No longa, pessoas pobres do hemisfério sul aceitam vender os direitos do uso de seus corpos a pessoas ricas do hemisfério norte para poderem sustentar a família. Vint ainda aponta que o filme é um dos poucos a humanizar ambos os lados: os exploradores e os explorados. O corpo como commodity também orienta o artigo de Suppia sobre o mexicano (em coprodução com os EUA) Sleep dealer (2008), de Alex Rivera. Suppia empresta os conceitos de "trabalho imaterial" e "capitalismo cognitivo" dos filósofos marxistas Antonio Negri e Michael Hardt (HARDT; NEGRI, 2000) para demonstrar as mudanças das relações trabalhistas em Sleep dealer, que mostra um México refém de corporações norte-americanas. A Ewa Mazierska interessa como o corpo físico se insere num mundo de realidades e jogos virtuais, tendo como base de estudo a coprodução Japão-Polônia Avalon (2001), de Mamoru Oshii, e o hollywoodiano Gamer (2009), de Mark Neveldine e Brian Taylor. Ela argumenta que tais filmes apontam as contradições do discurso neoliberal: enquanto empresários e governos promovem os jogos e o mundo virtual como benesses para todos, jogar não é necessariamente um ato voluntário, mas sim uma maneira sutil de coerção.

Ewa Mazierska e Alfredo Suppia ("Capitalism and wasted lives in District 9 and Elysium", capítulo 5), e Mariano Paz ("Rags and revolution: visions of the Lumpenproletariat in Latin American zombie films", capítulo 9), por sua vez, 
discutem os conceitos de lumpemproletariado e de desemprego estrutural nos filmes do sul-africano Neill Blomkamp e em filmes de zumbi latino-americanos. Distrito 9 (District 9, 2009) e Elysium (2013), ambos de Blomkamp, oferecem, segundo Mazierska e Suppia, um diagnóstico marxista do capitalismo neoliberal, em que o sistema econômico gera um desemprego estrutural e um exército industrial de reserva e em que o estado é incapaz de manter os direitos humanos frente à exploração econômica, gerando, inclusive, uma massa de lumpemproletariado. Já para Paz, em filmes como o cubano Juan dos mortos (Juan de los muertos, 2011), de Alejandro Brugués, e a trilogia argentina Plaga zombie (1997, 2007 e 2012), de Pablo Parés e Hernán Sáez, os zumbis, ao contrário dos filmes hollywoodianos, representam os próprios lumpemproletariados, uma horda de vagabundos, pequenos criminosos, desempregados e renegados. Segundo o autor, a condição de lúmpen é uma consequência de uma sociedade pouco inclusiva. Para demonstrar tal, Paz se apoia no contexto histórico local em que os filmes foram produzidos e nos conceitos de "resíduos humanos", de Zygmunt Bauman, para Plaga zombie, e de "multitude", de Antonio Negri e Michael Hardt (HARDT; NEGRI, 2006), para Juan dos mortos.

Mais deslocado dos demais artigos, o capítulo 6, "Marxism vs. Postmodernism: the case of The Matrix", de Tony Burns, busca comprovar que a leitura marxista é muito mais interessante para compreender o hollywoodiano Matrix (1999), dos irmãos Wachowski, do que a pós-modernista, a qual geralmente é associado. Burns, assim, à medida que desconstrói os argumentos pós-modernistas, amparados por Jean Baudrillard, em seis questões, encontra saídas marxistas para os mesmos problemas.

\section{Cinema e história}

Red alert: Marxist approaches to science fiction cinema, assim, insere-se numa linha que busca pensar o cinema de gênero e a ficção científica como investigação histórica. Independentemente da intenção dos criadores, os filmes transbordam uma série de nuances que podem prover conteúdo para a análise de determinado contexto histórico. Os filmes de ficção científica, por conta de seu caráter urgente e atual - geralmente encobertos por uma camada metafórica da ordem do fantástico -, servem como retrato da época em que a obra foi realizada.

Conforme aponta Marc Ferro, os filmes "não constituem somente um testemunho sobre o imaginário da época em que foram feitos; eles comportam elementos que têm um maior alcance, trazendo até nós a imagem real do passado" (FERRO, 2010, p. 60). 
Os ensaios de Red alert são todos guiados por uma ideia de materialismo histórico - em que a sociedade é orientada pelas atividades econômicas - e buscam diagnosticar como os filmes analisados, que exageram aspectos da contemporaneidade, refletem a própria realidade local. Ainda que desiguais em termos de profundidade e de sucesso em relação à proposta (os textos de Burns e de Bould parecem especialmente deslocados do conjunto), Red alert avança na compreensão do cinema de ficção científica.

Há de se destacar que Red alert faz parte do esforço do pesquisador e professor Alfredo Suppia, da Unicamp, em dar visibilidade aos estudos de gêneros narrativos, em especial ao cinema de ficção científica, após livros como A metrópole replicante: construindo um diálogo entre Metrópolis e Blade runner, lançado pela UFJF, em 2011 , fruto de sua pesquisa de mestrado, Atmosfera rarefeita: a ficção científica no cinema brasileiro, publicado pela Devir, em 2013, oriundo de seu doutorado, e Gêneros cinematográficos e audiovisuais: perspectivas contemporâneas, lançado pela Margem da Palavra, em 2016, que organizou, entre outros. Espera-se, agora, que os leitores brasileiros também possam desfrutar desse recente trabalho.

\section{Referências}

FERRO, M. Cinema e história. 2. ed. Tradução Flávia Nascimento. Rio de Janeiro: Paz e Terra, 2010.

HARDT, M; NEGRI, A. Empire. Cambridge, MA: Harvard University Press, 2000.

HARDT, M; NEGRI, A. Multitude. London: Penguin, 2006.

MARZIESKA, E; SUPPIA, A. Red alert: Marxist approaches to science fiction cinema. Detroit: Wayne State University Press, 2016.

submetido em: 8 set. 2017 | aprovado em: 2 out. 2017 